\title{
Problems with Magic Bullets: Future Trials and Multiagent Therapy
}

\author{
Arthur E. Baue
}

Although nobody really believes it, let us pretend that inflammation really exists as an entity among biologic mechanisms.... The end result [of inflammation] is not defense; it is an agitated, committee-directed harem-scarum effort to make war. -Lewis Thomas. ${ }^{1}$

The explosion of knowledge about mediators of inflammation, injury, and infection has been impressive. These topics are described in other chapters in this book and are summarized in Table 57.1. Antagonists to all of these substances have been produced as monoclonal antibodies, receptor antagonists, or other enzymes or blocking agents; and many have been tried clinically. Many of these agents and the clinical trials have been reviewed by Neugebauer et al. ${ }^{2}$ The frequency of infection, sepsis, injury, or inflammation in producing multiple organ failure led to clinical trials of these so-called magic bullets for the treatment of patients with sepsis and after injury. These trials have had limited success or negative results, despite considerable evidence of the efficacy or protection by such agents in experimental animals and in studies of human volunteers. I believe the major reasons for these negative results have been (1) the use of general entry criteria for the trials rather than the treatment of specific diseases or injuries and (2) the redundancy and overlap of these complex, interacting substances. Thus the "magic bullet" approach has failed because it oversimplifies a complex biologic system. ${ }^{3}$

The results of another negative randomized double-blind placebo controlled multicenter phase III trial have now been published indicating that platelet-activating factor receptor antagonists in patients with severe gram-negative bacterial sepsis did not improve the mortality rate. ${ }^{4}$ This report was accompanied by an editorial "The Siren Song of Confirmatory Sepsis Trials" on selection bias and sampling error. ${ }^{5}$ Perhaps it is simply that a single nonspecific agent does not do anything in the treatment of infected patients.

\section{Remote Organ Damage}

An overwhelming inflammatory process initiated by a disease or injury may jeopardize the patient. Such a life-threatening process is produced by a multitude of mediators that are activated nonspecifically by a host of abnormalities ranging from trauma to infection to myocardial infarction and to a low cardiac output in patients who have undergone an operation for cardiac disease.

Damage to a remote organ such as the lung occurs with ischemia/reperfusion injury of the lower extremities or the gastrointestinal tract. It may also occur with infections such as peritonitis. The response to injury, infection, ischemia, and inflammation is a complex, multimediated, overlapping, redundant system. Many experimental and clinical models indicate the virulence of such an uncontrolled response and the problems produced by mediators. Such an autodestructive phenomenon was suggested by Ehrlich and Morganroth in 1901 when they described the possibility of an autoimmune response they called a potential "horror autotoxicus." I have referred to overwhelming inflammation as a modern horror autotoxicus. ${ }^{7}$ Thus overwhelming inflammation can jeopardize a patient, no matter what its cause, but there is no single mediator that causes most or all of the trouble.

An inflammatory response is also a major defense for the host. It helps to heal wounds, control infection, and support the individual during stress. Inflammation is necessary for survival. If it is necessary but becomes excessive with severe illness, can we control the excess without interfering with what is needed? Natural reactions and substances produced by patients for controlling an excessive inflammatory response are being identified and evaluated. They include the antiinflammatory cytokinases, natural receptor antagonists, and bacterial permeability increasing BPIP protein to bind endotoxin. All biologic reactions have such feedback loops or control mechanisms. These substances have been or will be evaluated in patients. The importance of the stage at which a patient is in the proinflammatory state or the later antiinflammatory state is emphasized.

\section{Can We Modulate Inflammation?}

Can we fool Mother Nature by blocking, stimulating, or replacing the substances and abnormalities of an inflammatory response? So far the many clinical trials based on legitimate, important, basic research on proven substances to control sepsis 
TABLE 57.1. Mediators of Injury, Inflammation, and Infection.

Platelet-activating factors

Endotoxin

Interleukins

Tumor necrosis factor

Cyclooxygenase metabolites

Bradykinin

Endorphins

Adhesion molecules

Nitric oxide

White blood cell products/elastase

Superoxide radicals

Complement

The explosion of knowledge about mediators of inflammation, injury, and infection has been impressive. These mediators are described in other chapters in this book and are summarized here. Antagonists to all of these substances have been produced as monoclonal antibodies, receptor anatagonists, or other enzymes or blocking agents; many have been tried clinically. Many of these agents and the trials have been reviewed by Neugebauer et al. ${ }^{2}$

or an excessive inflammatory response have all been negative. The endpoint in most if not all of these studies was mortality within 28 days. These trials included HA-1A monoclonal antibodies to endotoxin, J-5 monoclonal antibodies to entotoxin, antitumor necrosis factor (TNF) antibodies, an interleukin-1 (IL-1) receptor antagonist, soluble TNF receptors, a TNF receptor-fusion protein, platelet-activating factor antagonists, a bradykinin antagonist, taurolidine, antithrombin III concentrate, and interferon- $\gamma($ IFN $\gamma)$. Dellinger ${ }^{8}$ has reviewed these trials, questioning whether new trials based on post hoc analysis of a previous trial can be successful. Previous attempts have not succeeded.

Danner et al., ${ }^{9}$ Natanson et al., ${ }^{10}$ Suffredini et al., ${ }^{11}$ and Eichacker et al. ${ }^{12}$ from the National Institutes of Health each presented papers at a recent shock forum in Vienna, Austria. They suggested that the therapeutic premise of benefit from inhibiting endotoxin or host inflammatory mediators in patients with sepsis or septic shock may be flawed and that inhibition of neutrophils by monoclonal antibodies to adhesion molecules may be deleterious. Inhibition of nitric oxide may produce more harm than good. Antiendotoxin strategies may work only if used before the insult. A monoclonal antibody to TNF protects against an injection of endotoxin (intravascular insult), ${ }^{13}$ but anti-TNF monoclonal antibodies increase the mortality associated with peritonitis in animals (intraperitoneal infection). ${ }^{14} \mathrm{IL}-1$ receptor antagonist (IL-1ra) and $\mathrm{IL}-1$ in small doses protected animals from Klebsiella pneumoniae, whereas larger doses of IL-1ra increased lethality. ${ }^{15}$ TNF and IL-1 are thought to produce many of the systemic manifestations of inflammation, but they are also necessary in certain circumstances. Cannon et al. ${ }^{16}$ concluded that "the association of mortality for burned patients with low circulating IL-1 $\beta$ indicates that it is an essential mediator of host defense." Luger et al. ${ }^{17}$ found that decreased serum IL-1 levels predicted death in patients with sepsis. Many other examples of such biologic conundrums exist. Thus the complexity and heterogeneity of the underlying disease processes and their life-threatening manifestations, the contradictory underlying pathologic processes, and the complex and redundant mediator-inflammatory system indicate that we have much to learn.

\section{Suggestions for Future Studies}

One recommendation is to use alternative or surrogate endpoints, such as a reduction in the severity of illness score, decreased intensive care unit (ICU) time, decreased time on a ventilator, and other evidence of clinical improvement. This is all well and good, but if the clinically improved patients die as frequently as the controls what have we accomplished?

Another recommendation was to perform randomized trials only in patients at high risk of dying, such as with a high Acute Physiology and Chronic Health Evaluation (APACHE III) score. Some believe that rapid identification of circulating endotoxin, gram-negative bacteremia, and other evidence of infection can help. I believe there is an even more important recommendation: to emphasize treating specific diseases in these trials, rather than just the inflammatory manifestations. The patient who has undergone multiple forms of trauma is different from the patient with a perforated ulcer or a perforated colon with peritonitis; and both are different from the patient with a urinary tract infection, pancreatitis, necrotizing pneumonia, or end-stage chronic obstructive pulmonary disease with pneumonia. The criticisms of my recommendation are that trials based on specific problems or diseases take longer and it is more difficult to accumulate a sufficient number of patients. This is true, but the present approach is not working. Most previous and successful "magic bullets," such as penicillin and smallpox vaccination, were slow in development, and all treated or prevented specific diseases (e.g., the poliomyelitis vaccine). On the other hand, nonspecific remedies, such as aspirin and nonsteroidal antiinflammatory agents, help patients feel better, but they do not cure or treat the disease. Another proposal is to consider multiagent therapy.

\section{Multiple Therapeutic Agents for Other Diseases}

There are many human diseases for which multiple agents are required for appropriate therapy. They include antituberculous therapy for tuberculosis, immunosuppression for transplanted organs, inotropes and diuretics for heart failure, multiple antibiotics for polymicrobial peritonitis, cancer chemotherapy, and support of the gastrointestinal tract. A review of several of these disease processes illustrates the difficulties and the evolution that occurred in therapy with multiple agents.

The development of chemotherapy for tuberculosis and its evolution over the years serves as an example of the problems even when dealing with a specific disease and one organism-which may be typical or atypical and may develop resistance to antibiotics. Waksman and colleagues isolated streptomycin in $1994 .{ }^{18}$ It was found to be effective against 
tuberculosis in a small trial in $1945,{ }^{19}$ followed by a large national trial in 1947 , with impressive clinical results. ${ }^{20}$ It was immediately evident, however, that there was a high incidence of relapse and development of resistant organisms. ${ }^{21}$ To counteract this effect, $p$-aminosalicylic acid (PAS), a drug that had mild tuberculostatic activity, was used in combination with streptomycin in a trial in 1948-1949. ${ }^{22}$ PAS extended the time during which streptomycin could be administered without the bacteria developing resistance.

In 1950 a specific program by industry led to the development of a synthetic antituberculous agent called isonicotinic acid hydrazide (INH), or isoniazid. It was highly effective in vitro and was strikingly successful in patients in $1952 .{ }^{23}$ It ushered in the modern era of chemotherapy. Other drugs were then developed.

The present recommended basic treatment for previously untreated patients with pulmonary tuberculosis is initial therapy with isoniazid, rifampin, and pyrazinamide given daily for 2 months followed by 4 months of isoniazid and rifampin. ${ }^{24}$ Ethambutol can be added during the initial 2 months if there is any suspicion of resistance or if the patient is thought to be infected with human immunodeficiency virus (HIV).

Thus there has been a steady and continuing evolution of appropriate multiagent chemotherapy for tuberculosis. We are reminded, however, that tuberculosis is a single disease that primarily involves the lungs initially even though there are variations in the organism (e.g., from typical to atypical to resistant). Much of the development of successful treatment of tuberculosis was done by in vitro studies of the organism in culture and then trial and error clinically. ${ }^{25,26}$ Also, each of the agents used in combination was effective for some time when used singly.

The development of cancer chemotherapy is another example of the complexities and difficulty of treating the manifestations and causes of human disease. Cancer chemotherapy was initially modeled after the multiagent treatment of tuberculosis. Paul Ehrlich coined the word "chemotherapy" at the turn of the century. He used rodent models of infectious diseases to develop antibiotics, which led Clowes at Roswell Park Memorial Institute during the early 1900s to develop inbred rodent lines to carry transplanted tumors to screen for potential anticancer drugs. ${ }^{27}$

The first modern chemotherapeutic agents were a product of a secret gas program in both World Wars. There was an explosion in Bari Harbor during World War II, and seamen were exposed to mustard gas, which caused bone marrow and lymphoid suppression. ${ }^{28}$ This led to trials in patients with hematopoietic neoplasms such as Hodgkin's disease and lymphocytic lymphomas. Chemotherapy was first attempted at the Yale Cancer Center in 1943. Because of the secret nature of the wartime gas program, these results were not published until $1946 .{ }^{29}$ Initially, there was great excitement because of regression of the neoplasms, but it was followed by discouragement because the tumors always grew back.

Farber then observed that folic acid accelerated leukemia, so folic acid antagonists were developed. ${ }^{30}$ Early therapy for childhood leukemias and Hodgkin's disease was with combination chemotherapy. There was then a long period of trial and error, observation of chemotherapy failures, and many other problems. DeVita stated that, with some exceptions (choriocarcinoma and Burkitt's lymphoma), single drugs and standard doses do not cure cancer. ${ }^{31}$ During the early years of chemotherapy, drug combinations were developed based on known biochemical actions of available anticancer drugs rather than on their clinical effectiveness. They were largely ineffective. DeVita stated that the era of effective combination chemotherapy began when an array of active drugs from different classes became available for use in combination for the treatment of leukemias and lymphomas. ${ }^{31} \mathrm{He}$ concluded that for multiagent cancer chemotherapy only drugs known to be partially effective against the same tumor when used alone should be selected for use in combination. The least toxic drugs should be used given in an optimal dose and schedule. The principle of cancer chemotherapy has been based on clinical trials designed and dominated by the use of alternating cycles of combination chemotherapy. ${ }^{32}$

The response to chemotherapy is affected by the biology of the tumors' growth, and all cancers are different. They respond to different agents. What is effective against one malignancy may do nothing for another. Malignancy is not a common denominator for therapy. Some tumors are hormone-dependent, some respond to radiation therapy, some respond to chemotherapy and various combinations, some respond to both, and some respond to operation with or without adjuvants. Staging and grade also have a lot to do with this. It is apparent now that permanent cure of malignancy is unusual, and the malignant setting in patients is important in terms of oncogeny influence, genetic mutations, and other factors.

The lessons learned from the treatment of tuberculosis and cancer indicate that specific diseases must be treated by a combination of agents, each of which has been shown to be effective individually in some way, shape, or form. In addition, these processes of infection and neoplasia are chronic; they are not immediate, acute, life-threatening problems. Treatment can be carried out over many weeks. There are many dissimilarities between the use of multiple chemotherapy for these diseases and the possibility of using agents for the control of acute inflammation and of acute, life-threatening systemic inflammatory response syndrome (SIRS), multiple organ dysfunction syndrome (MODs), and multiple organ failure (MOF).

\section{Experimental Studies of Multiple Agents for Inflammation}

Therapy for excessive inflammation could require control or replenishment of a number of agents shown in Table 57.2. Several years ago, Redl and Schlag hosted a shock conference in Vienna during which a number of speakers presented models for the use of multiple agents or multiple-component therapy for the treatment of sepsis and septic shock in critically ill surgical patients. Aasen and colleagues from Oslo, Norway, presented a study conducted in a pig model receiving endotoxin. They used a combination of three protease inhibitors ( $\mathrm{C} 1$ inhibitor, antithrombin III, aprotinin) together with methylprednisolone, 
TABLE 57.2. Therapy for Excessive Inflammation to Control Proinflammatory Mediators.

Endotoxin

Proinflammatory cytokines

Bradykinin

Proteinases

Oxygen radicals

Coagulation activation

Adhesion molecule expression

Complement activation

Cyclooxygenase and lipoxygenase activation

Histamine stimulation

naloxone, ketanserin, and promethazine. ${ }^{33}$ This "cocktail" protected the animal against endotoxin-induced changes in the plasma enzyme cascade systems. At the same meeting Opal and colleagues from Brown University used an established infection model of Pseudomonas sepsis and treated the animals with a combination of a J-5 antisera, an opsonophagocytic monoclonal antibody (mAb), and an anti-TNF mAb. ${ }^{34}$ They found that it provided significantly greater protection than single-component therapy.

Faist presented a hypothesis for a combined therapeutic strategy that included (1) global short-term $(<72$ hours) downregulation of inflammatory monocyte activity and polymorphonuclear neutrophils (PMNs) by drugs such as pentoxifylline and IL-10 or IL-13; (2) prevention of excessive monocyte/macrophage stimulation by neutralization of circulating endotoxins with high-dose polyvalent receptors; and (3) upregulation of cellmediated specific immune performance to overcome posttraumatic immune paralysis by administration of substances such as thymokinetic hormones [e.g., IFN $\gamma$ and granulocyte colonystimulating factor (G-CSF)]. ${ }^{35}$ This combination reflects a highly balanced view. At that conference Fischer suggested that a combination of agents could be helpful and should be evaluated. ${ }^{36}$ He listed BPIP for its antiendotoxin effects, IL-1ra for its anticytokine effects, antithrombin III to protect against the coagulation cascade, and a complement inhibitor to decrease the complement cascade.

There have been more recent studies that may alter these hypotheses and proposals. For example, Mannick et al. found that a monoclonal antibody to IL-10 restored resistance to a septic challenge in an animal model. ${ }^{37}$ Dalton et al. found that combined administration of IL-1ra and soluble tumor necrosis factor receptor (sTNF-r) decreased mortality and organ dysfunction in animals after hemorrhagic shock. ${ }^{38}$

\section{Glinical Studies of Multiple Therapeutic Agents}

Knox et al. used a combined chemotherapeutic regimen in burn patients in which they gave antioxidants, including vitamins $\mathrm{C}$ and $\mathrm{E}$ and glutamine, with an endotoxin binder (parenteral polymyxin B), a cyclo/lipoxygenase inhibitor (ibuprofen), and reconstituted human growth hormone. ${ }^{39}$ They believe that this combination lowered the mortality rate based on a comparison with historical controls.

Kirton et al. use a three-arm strategy in trauma patients. ${ }^{40}$ First, they block free radical production; next they provide scavengers; and then they bolster the patients' natural defenses by infusing mannitol, folate, hydrocortisone, selenium, lidocaine, polymyxin $\mathrm{B}$, vitamin $\mathrm{G}$, and Zantac. This phase is followed by a maintenance infusion of these substances and a gut formula given enterally containing glutamine, acetylcysteine, and vitamins $\mathrm{A}$ and $\mathrm{E}$. In addition, they try to normalize gastric $\mathrm{pH}(\mathrm{pHi})$ by circulatory support. They believe that they have been able to maintain the same mortality rate with this regimen despite increased severity of injury in the trauma patients treated. They also used historical controls.

Gott et al. studied risk reduction with cardiopulmonary bypass in patients. ${ }^{41}$ They found that pharmacologic and mechanical strategies to blunt the inflammatory response to cardiopulmonary bypass improved patient outcome significantly and were highly cost-effective. They used methylprednisolone, aprotinin, leukocyte filtration, and heparin-bonded circuitry.

A review of the randomized trials of agents evaluated for sepsis or SIRS (potential magic bullets) shows that there was some benefit for patients in some of the trials even though the 28-day mortality rate was not improved. I review only several examples here, although there are many others.

Supplementation of antithrombin III (AT III) in patients with severe sepsis did not improve overall mortality, although treated patients required fewer days of ventilatory support, spent less time in the ICU, and had decreased organ failure. ${ }^{42}$ In another study, AT III resolved disseminated intravascular coagulation. The oxygenation index $\left(\mathrm{PaO}_{2} / \mathrm{FiO}_{2}\right.$ ratio) improved, and pulmonary hypertension decreased. ${ }^{43}$ There was also a decreased rise in serum bilirubin and decreased need for renal support therapy. Thus it is possible that several such agents could, when combined, provide overall benefits for patients. These treatments, however, are costly. What will be the result?

Potential hazards of combination immunotherapy were described by Opal et al., who gave a combination of anticytokines, aTNF-binding protein, and a recombinant human IL-1 ra to a Pseudomonas aeruginosa model in neutropenic rats. This regimen resulted in death of all animals due to disseminated microabscesses. ${ }^{44}$

There are many difficulties when evaluating a multiagent therapeutic trial, particularly when we are dealing with injury, operation, sepsis, and inflammation and not a specific disease process. Whether anyone will ever be able to demonstrate the worthwhileness of a multiagent therapeutic approach remains to be determined. Certainly single agents that block various individual mediators have not been the answer.

\section{Ideal Combinations of Agents}

Because of the many mediators, each of which seems to have a role in the pathogenesis of excessive inflammation, it makes scientific sense to use multiple agents. If we tried to put together 
TABLE 57.3. Agents Requiring Replenishment.

Antiinflammatory mediators

Antioxidants

Immunostimulators

an ideal combination of agents for excessive inflammation, what would be the components? Certainly, early on in the disease process some attempts to block proinflammatory mediators (Table 57.2) should be worthwhile. Soon thereafter supplemental antiinflammatory mediators seem necessary (Table 57.3).

Included should be control of the many enzyme cascades that are activated by shock, trauma, or infection (Table 57.4). How many of these it is necessary or important (or even possible) to block is not known. How do we begin to formulate such an approach? What is the timing? What is the cost? If the multiagent cocktail becomes beneficial, what ingredients are critical? Some may be ineffective.

What is the model on which to test such approaches? One example is the sheep model developed by Dwenger et al. ${ }^{45}$ The models were reviewed by Redl et al. ${ }^{46} \mathrm{~A}$ baboon model in the final development stage could be helpful for multiagent testing. ${ }^{46}$ Would that fill the bill? Perhaps so, or do we also need new "multiple models" to cope with a "two- or multiplehit" theory as suggested. ${ }^{47}$ In any case, it is difficult to prepare a sufficient multidimensional protocol for such a study. We are told that the Food and Drug Administration (FDA) in the United States would probably not approve a multiagent

TABLE 57.4. Control of Enzyme Cascades Activated by Shock, Trauma, and Infection.

\begin{tabular}{l} 
Control of proinflammatory mediators \\
Scavenging of inducers \\
Endotoxin, recombinant bacterial permeability inhibitor ${ }_{21}\left(\mathrm{rBPI}_{21}\right)$ \\
Proinflammatory mediator blockade \\
Interleukin-1 receptor antagonist (IL-1ra) \\
Soluble tumor necrosis factor receptor (sTNFr) \\
Anti-TNF monoclonal antibody (mAb): to restore function \\
Supplementation of antiinflammatory agents \\
IL-10: to reduce inflammation \\
IL-12, IL-13 \\
Anti-IL-10 mAb to restore immune function \\
Recombinant high density lipoprotein (rHDL) \\
Antioxidants \\
Protease inhibitors \\
Tissue factor pathway inhibitor \\
Cascade control \\
Coagulation: antithrombin III (AT III) \\
Complement inhibitor \\
Cyclooxygenase and lipoxygenase inhibition: ibuprofen \\
Histamine antagonist \\
Bradykinin antagonist \\
Control of other factors \\
Platelet-activating factor (PAF) antagonist \\
Immunomodulators: drugs, diet \\
Antiadhesion agents \\
\hline
\end{tabular}

TABLE 57.5. Individual Therapies.

Pentoxifylline

AT III in septic patients

Enteral immunonutrition

High $\mathrm{DO}_{2}$ and $\mathrm{VO}_{2}$ in sick patients

Nitric oxide synthase with severe sepsis

G-GSF in septic patients

Omeprazole suspension

In-line heat moisture-exchange filter and heated wire

humidifiers in patients on ventilators

Each therapy modality provides some improvement in sick patients in an ICU but may not by itself change the mortality rate.

AT III, antithrombin III; $\mathrm{DO}_{2}, \mathrm{VO}_{2}$, delivery and utilization of oxygen; G-CSF, granulocyte colony-stimulating factor.

approach. However, all of the agents used by Demling's group, ${ }^{39}$ and Kirton et al. ${ }^{40}$ are already approved prescription drugs or are over-the-counter drugs. Does that allow them to be used in a multiagent cocktail without informed consent? I know of no opinion regarding that possibility. Perhaps a trial in Europe would help. In the meanwhile, we may learn more from the use of multiple agents in animal studies.

Other therapeutic contributions make good sense clinically, but the evidence is divided over the worthiness of the effort (Table 57.5). They may help in some patients. Some of them are also controversial, with some trials indicating clinical improvement and others failing to document such changes (Table 57.6). Some may improve a patient's condition but not decrease mortality. None has been accepted universally. All of the protocols have active supporters and some distractors. For example, in a randomized trial of early enteral nutrition in patients having major operations Heslin et al. ${ }^{48}$ found no benefit, whereas Braga et al. in a randomized trial after abdominal surgery ${ }^{49}$ and Bryg and Beale in a meta-analysis found that enriched enteral nutrition decreased the severity of infection, length of hospital stay, and days on a ventilator-but there was no change in mortality. ${ }^{50}$ Immediate postoperative enteral feeding may decrease mobility and impair respiratory mechanics. In general, most believe that early immuneenhanced enteral feeding is worthwhile when tolerated by the patient.

Measurement of gastric intramucosal $\mathrm{pH}(\mathrm{pHi})$ has been found to be helpful in resuscitation and patient care, but it is cumbersome to use and has not been universally adopted. Those who have used this monitoring technique have found it helpful for improving blood flow to the gut (perhaps microcirculatory flow) and outcome. Increasing the pHi to normal has been associated with decreased mortality. ${ }^{51,52}$ The use of air in the balloon rather than saline has made the technique much easier (see Chapter 25).

Another example is the result of a randomized phase III trial of inhaled nitric oxide (NO) for patients with acute respiratory distress syndrome (ARDS). Dellinger et al. found that NO was well tolerated and produced a significant improvement in oxygenation $\left(\mathrm{PaO}_{2}\right)(>20 \%)$ in $60 \%$ of patients, but there was no change in overall mortality or in the number of days alive 
TABLE 57.6. Therapy That Is Controversial When Used in All ICU Patients but Is Sometimes Useful in Certain Situations.

\begin{tabular}{ll}
\hline Therapy & \multicolumn{1}{c}{ Purpose } \\
\hline Selective gut decontamination & Acute liver failure, burns, pancreatitis \\
Inhaled NO & Certain patients with ARDS \\
Intraoperative maintenance of & Prevents ARDS in surgical patients \\
$\quad$ tissue perfusion & \\
Protective ventilation strategy & Improved weaning \\
Avoiding ranitidine & May increase infections \\
Lexipafant (PAF antagonist) & Acute pancreatitis \\
Venovenous hemofiltration & Septic patients \\
Inhaled NO & Patients with ARDS after pulmonary \\
& resection \\
ECMO & End-stage ARDS \\
rhGH & Short bowel syndrome \\
rhG-CSF & Septic patients with neutropenia \\
Partial liquid ventilation & Trauma patients \\
N-Acetylcysteine & Acute lung injury \\
Avoid hypothermia & Decreases mortality with trauma, \\
& and wound infections after \\
rBPI & abdominal operations \\
Enalaprilat & After liver resection \\
Selenium & Improves gut perfusion in injured \\
PGE & patients \\
Plasma G1 INH & Improves clinical outcome and \\
(complement inhibitor) & decreases acute renal failure \\
Ventilation with & May decrease mortality in trauma \\
(1) prone position, & patients \\
(2) kinetic therapy bed, & Patients seem improved \\
Lysophyline & \\
& Alleviates ARDS \\
Hypertonic 7.5\% saline and/or & \\
\hline No dextran 70 & Resuscitation particularly with head \\
& injury patients \\
\hline & \\
&
\end{tabular}

No, nitric oxide; PAF, platelet-activating factor; ECMO, extracorporeal membrane oxygenation; rhGH, recombinant human growth hormone; rhG-CSF, recombinant human granulocyte colony-stimulating factor; $\mathrm{PGE}_{1}$, prostaglandin $\mathrm{E}_{1}$; ARDS, acute respiratory distress syndrome; IL-2, interleukin-2; rBPI recombinant bacterial permeability inhibitor.

and off mechanical ventilation. ${ }^{53}$ The same results were also seen in surgical patients. One editorialist group described it as a negative study, ${ }^{54}$ whereas Zapol described the results as potentially positive. ${ }^{55} \mathrm{He}$ urged the use of $\mathrm{NO}$ in patients with ventilatory failure alone (no other problems). This raises the question as to whether ARDS is truly a syndrome-it is not a disease. Perhaps some diseases that produce respiratory failure are susceptible to inhaled NO and others are not. It is worth a try.

Mathisen et al. have reported the early use of inhaled NO in patients developing ARDS after lung resection (a more homogeneous group). ${ }^{56}$ Previously the mortality in their experience was $85.7 \%$. With $\mathrm{NO}$, the $\mathrm{PaO}_{2} / \mathrm{FiO}_{2}$ ratio and chest radiographs improved progressively in all patients. Seven of the ten patients survived. The three who died had sepsis, and none died of ARDS. Patients with ARDS who require ventilator support seem to benefit from rotational kinetic therapy and positioning in a prone position from time to time. Other ventilator strategies that seem to help include inverse-ratio ventilation and permissive hypercapnia.

Patients who achieve adequate or high oxygen transport $\left(\mathrm{DO}_{2}\right)$ and oxygen consumption $\left(\mathrm{VO}_{2}\right)$ after an injury or operation or with an illness are said to be more likely to survive. ${ }^{57}$ Some believe that if a treatment can drive oxygen transport and oxygen consumption to supernormal values, the chances of survival are increased. Others have found evidence to the contrary. All in all, if one is sick it is better to have high $\mathrm{DO}_{2}$ and $\mathrm{VO}_{2}$ unless it is artificially increased by catecholamines. ${ }^{58} \mathrm{It}$ has been known for many years that patients after injury, after operation, or with sepsis must be able to increase the cardiac index to survive.

Hypertonic solutions (saline-dextran) have been found to be of great benefit in animal experiments ${ }^{59}$ and of some benefit in clinical trials. However, the benefit has not been enough to recommend that they be used commonly or routinely. ${ }^{60}$ The same is true for synthetic colloids such as pentastarch, which is safe and efficient and reduces intravenous volumes required for resuscitation. ${ }^{61}$ One situation where hypertonic solutions may be of value is in patients with head injury. ${ }^{62}$ Such solutions do not increase intracranial pressure and, in fact, tend to decrease it. Whether the use of hypertonic solutions for resuscitating trauma patients would result in a more rapid increase in microcirculatory blood flow and improve their overall situation has not been established. ${ }^{63}$

Thangathurai et al. maintained intraoperative tissue perfusion by nitroglycerin and fluids in high risk patients. ${ }^{64}$ None of 155 such patients developed ARDS. This is a promising, physiologic approach to patient care and requires verification.

Pentoxifylline has a number of admirable qualities demonstrated in experimental animals, such as restoring cardiac performance and tissue perfusion and decreasing susceptibility to sepsis. Thus it should be worthwhile clinically. Two clinical trials have suggested some hemodynamic improvement, such as increased $\mathrm{DO}_{2}$ and $\mathrm{VO}_{2} \cdot{ }^{65,66}$ Whether these changes are enough for this agent to be used more widely remains to be determined.

Some have found selective gut decontamination to be worthwhile in general ICU patients, whereas others have found no benefit in trauma ICU patients. Sun et al., in an metaanalysis, suggested that the possibility that this therapy reduces mortality is significantly better in patients with a high mortality risk at study entry. ${ }^{67}$ Selective gut decontamination seems to be therapy in search of the right patient. When this modality was used in patients with specific disease processes, such as acute pancreatitis where gut bacteria may play a role, there was reduced mortality and general improvement. ${ }^{68}$ Baxby et al. reviewed the 13-year history of selected decontamination in 46 trials. They recommended treating specific problems: patients with liver disease or burns and medical patients after some days in the ICU on mechanical ventilation. ${ }^{69}$

Extracorporeal membrane oxygenation (ECMO) has allowed survival of some patients with severe respiratory failure who were not improved by other means. These patients would certainly have died otherwise. ${ }^{70}$ 
Hirasawa et al. continue to use hemodiafiltration in ICU patients. $^{71}$ They found decreased cytokine mediators and an improved respiratory index and tissue oxygenation in patients with ARDS who received this treatment. Honore et al. also reported benefit from this therapy. ${ }^{72}$

There are many other experiences and therapies that could be cited and may be worthwhile. In this survey, I have given some examples and have not tried to be exhaustive in reviewing them. Are these studies then negative or positive? Some help is provided but not enough to decrease the death rate in the treated patient. I now favor another interpretation. In complex clinical situations and in very sick patients, adjunctive or supplementary therapy may help the patient but it requires more than a single intervention to improve mortality. It is also possible that such an intervention is helpful in a certain group of patients but not in others. If you spread too wide a net for entry into a study, the results may be negative because of so many different disease processes in sick patients in the study.

\section{Conclusions and Recommendations}

I recommend that we study what agent or agents help with certain clinical problems, situations, or diseases, such as burns, pancreatitis, multiple trauma, peritonitis, and ventilator-associated pneumonia. In addition, we must distinguish septic shock with gram-negative organisms from that with gram-positive organisms and fungus infections. We must distinguish ARDS patients with chronic obstructive pulmonary disease from patients with ARDS after thoracic surgery, patients after chest trauma, and other medical patients with ARDS. There are many questions that arise and must be answered. Treating sick patients by nonspecific therapy for their disease or diseases has not helped. We have learned that lesson.

\section{References}

1. Thomas L: Adaptive Aspects of Inflammation Symposium of the International Inflammation Club. Kalamazoo, Upjohn, 1970.

2. Neugebauer E, Rixen D, Raum M, Schafer U: Thirty years of antimediator treatment in sepsis and septic shock: what have we learned? Langenbecks Arch Surg 1998;383:26-34.

3. Baue AE: Multiple organ failure, multiple organ dysfunction syndrome and systemic inflammatory response syndrome: Why no magic bullets? Arch Surg 1997;132:703-707.

4. Dhainaut J, Tenaillon A, Hemmer M, et al: Confirmatory plateletactivating factor receptor antagonist trial in patients with severe gram-negative bacterial sepsis: a phase III, randomized, doubleblind, placebo-controlled, multicenter trial. Crit Care Med 1998;26:1963-1972.

5. Natanson C, Esposito CJ, Banks SM: The sirens songs of confirmatory sepsis trials: selection bias and sampling error. Crit Care Med 1998;26:1927-1932.

6. Ehrlich P, Morganroth J: Ueber Hamolysins: Füntte Mittheilung. Berl Klin Wochenschr 1901;38:251-257.

7. Baue AE: The horror autotoxicus and multi-organ failure. Arch Surg 1992;127:1451-1462.
8. Dellinger RP: Post hoc analyses in sepsis trials: a formula for disappoinment? Crit Care Med 1996;24:727-729.

9. Danner RL, Cobb JP, Suffredini AF, Eichacker PO, Natanson C: Nitric oxide in sepsis: role in inflammation and shock. Shock 1995;3(Suppl):61-62.

10. Natanson C, Eichacker PO, Suffredini AF, Danner DL: Selected treatment strategies for septic shock based on proposed mechanisms of pathogenesis. Shock 1995;3(Suppl):62.

11. Suffredini AF, Natanson G, Danner RL, Suffredini AF: The neutrophil as a therapeutic target in septic shock. Shock 1995;3(Suppl):62-63.

12. Eichacker PO, Natanson C, Danner RL, Suffredini AF: The neutrophil as a therapeutic target in septic shock. Shock 1995;3 (Suppl):62-63.

13. Tracey KJ, Fung $Y$, Hesse KR, et al: Anti-cachectin/TNF monoclonal antibodies prevent septic shock during letal bacteremia. Nature 1987;330:662-664.

14. Echtenacher B, Falk W, Mannel DN, Krammer PH: Requirement of endogenous tumor necrosis factor/cachectic for recovery from experimental peritonitis. J Immunol 1990;145: 3762-3766.

15. Mancilla J, Garcia P, Dinarello CA: The interleukin-1 receptor antagonist can either reduce or enhance the lethality of Klebsiella pneumonia sepsis in newborn rats. Infect Immun 1993;61: 926-932.

16. Cannon JG, Friedberg JS, Gelfand JA, et al: Circulating interleukin-1 beta and tumor necrosis factor-alpha concentrations after burn injury in humans. Crit Care Med 1992;20:1414-1419.

17. Luger A, Graf H, Schwartz H-P, Stummvoll H-K, Luger TA: Decreased serum interleukin 1 activity and monocyte interleukin 1 production in patients with fatal sepsis. Crit Care Med $1986 ; 14: 458-461$.

18. Schatz A, Bugie E, Waksman SA: Streptomycin, a substance exhibiting antibiotic activity against gram-positive and gramnegative bacteria. Proc Soc Exp Biol Med 1944;4:66-69.

19. Hinshaw HC, Feldman WH: Streptomycin in treatment of clinical tuberculosis: a preliminary report. Proc Staff Meet Mayo Clin 1945;20:313-318.

20. Hinshaw HG, Plye MM, Feldman WH: Streptomycin in tuberculosis. Am J Med 1947;2:429-435.

21. McDermott W, Muschenheim C, Hadley SJ, et al: Streptomycin in the treatment of tuberculosis in humans. Ann Intern Med 1947;27:769-822.

22. Medical Research Council: Treatment of pulmonary tuberculosis with streptomycin and para-aminosalicylic acid. BMJ 1950;2:1073-1085.

23. Robitzek EH, Selikoff IJ: Hydrazine derivative of isonicotinic acid (Rimifon, Marsalid) in the treatment of acute progressive caseouspneumonic tuberculosis: a preliminary report. Am Rev Tuberc 1952;65:402-428.

24. Committee on Treatment, International Union Against Tuberculosis and Lung Disease: Antituberculosis regimens of chemotherapy. Bull Int Un Tuberc Lung Dis 1988;63:60-64.

25. Tuberculosis Unit, Division of Communicable Diseases, World Health Organization: Guidelines for tuberculosis treatment in adults and children in national tuberculosis programs. World Health Organization 1991;WHO/TB91:161.

26. MacGregor RR: Treatment of myobacterial disease of the lungs caused by mycobacterium tuberculosis. In: A Fishman (ed) Pulmonary Diseases and Disorders. New York, McGraw-Hill, 1993;1869-1882. 
27. Marchall EK Jr: Historical perspectives in chemotherapy. In: Golden A, Hawking IF (eds) Advances in Chemotherapy, vol 1. San Diego, Academic, 1964;1.

28. Alexander SF: Final report of Bari mustard casualties. Allied Force Headquarters, Office of the Surgeon. APO 512, June 20, 1944.

29. DeVita VA: The evolution of therapeutic research in cancer. N Engl J Med 1978;298:807.

30. DeVita VT Jr: Principles of cancer management: chemotherapy. In: DeVita VT Jr, Hellman S, Rosenberg SA (eds) Cancer Principles \& Practice of Oncology, 5th ed, vol 1. Philadelphia, Lippincott-Raven, 1997;333-339.

31. DeVita VT Jr: The evolution of therapeutic research in cancer. Sounding Boards 1978;298:907-910.

32. DeVita VT Jr, Schein PS: Medical progress: the use of drugs in combination for the treatment of cancer, rationale and results. N Engl J Med 1973;288:988-1006.

33. Aasen AO, Naess E, Carlse H, et al: [abstract]. Shock 1995;3 (Suppl):65. Multi-agent therapy to protect against endotoxin.

34. Opal S, Cross AS, Sadoff JC, et al: Combined immunotherapy in the treatment of septic shock [abstract]. Shock 1995;3(Suppl):65.

35. Faist E: Immunomodulatory approaches in critically ill surgical patients [abstract]. Shock 1995;3(Suppl):65-66.

36. Fischer G: Unpublished discussion. Fifth Vienna Shock Forum, May 7-11, 1995.

37. Mannick JA, Lyons A, Kelly J, et al: Major injury induces increased production of $\mathrm{IL}-10$ by cells of the immune system with a negative impact on resistance to infection. Ann Surg (in press).

38. Dalton JM, Gore DG, DeMaria EJ, et al: Combined administration of interleukin-1 receptor antagonist (IL-IRA) and soluble tumor necrosis factor receptor (STNF-R) decreases mortality and organ dysfunction following hemorrhagic shock. J Trauma (in press).

39. Knox J, Demling R, Wilmore D, et al: Increased survival after major thermal injury: the effect of growth hormone therapy in adults. J Trauma 1995;39:526-530.

40. Kirton O, Windsor J, Civetta JOV, et al: Persistent uncorrected intramucosal $\mathrm{pH}$ in the critically injured: the impact of splanchnic and antioxidant therapy [abstract]. Crit Care Med 1996;24:A82.

41. Gott JP, Cooper FE, Schmidt, et al: Documentation of risk naturalization for extracorporeal circulation in four limbed, 400 patient, risk stratified, prospective, randomized trial. J Surg Res

42. Fourrier F, Chopin C, Huart JJ, et al: Double-blind, placebocontrolled trial of antithrombin III concentrates in septic shock with disseminated intravascular coagulation. Chest 1993;104: 882-888.

43. Inthorn D, Hoffmann JN, Hartl WH, et al: Antithrombin III supplementation in severe sepsis: beneficial effects on organ dysfunction. Shock 1997;8:328-334.

44. Opal SM, Cross A, Jhung W, et al: Potential hazards of combination immunotherapy in the treatment of experiment septic shock. J Infect Dis 1996;173:1415-1421.

45. Dwenger A, Remmers D, Gratz M, et al: Aprotinin prevents the development of the trauma-induced multiple organ failure in a chronic sheep model. Eur J Glin Chem Clin Biochem 1996;30:204-214.

46. Redl H, Schlag G, BahramI S, Yao YM: Animal models as the basis of pharmacologic intervention in trauma and sepsis patients. World J Surg 1996;20:487-492.

47. Moore E, Moore F, Franciose R, et al: The postischemic gut severes as a priming bed for circulating neutrophils that provoke multiple organ failure. J Trauma 1994;37:881.
48. Heslin MJ, Latkany L, Leung D, et al: A prospective: randomized trial of early enteral feeding after resection of upper GI malignancy. Ann Surg (in press).

49. Braga M, GianottI L, VignalI A, et al: Artificial nutrition after major abdominal surgery: impact of route of administration and composition of the diet. Crit Care Med 1998;26:24-30.

50. Bryg DJ, Beale RJ: Clinical effects of enteral immunonutrition on intensive care patients: a meta-analysis. Crit Care Med 1998;26:A91.

51. Ivatury RR, Simon RJ, Islam $S$, et al: A prospective randomized study of end points of resuscitation after major trauma. J Am Coll Surg 1998;183:145-154.

52. Ljubanovic M, Calvin J, PeruzzI W: Meta-analysis of gastric $\mathrm{pH}$ as determinant of mortality in critically ill patients. Crit Gare Med 1998;26:A123.

53. Dellinger RP, Zimmerman JL, Taylor RW, et al: Effects of inhaled nitric oxide in patients with acute respiratory distress syndrome: results of a randomized phase II trial. Crit Care Med 1998;26:15-23.

54. Mattay MA, Pittet JF, Jayr G: Just say NO to inhaled nitric oxide for the acute respiratory distress syndrome. Crit Care Med 1998;26:1-2.

55. Zapol WM: Nitric oxide inhalation in acute respiratory distress syndrome: it works, but can we prove it? Crit Care Med 1998; 26:2-3.

56. Mathisen DJ, Kuo EY, Hahn C, et al: Inhaled nitric oxide for adult respiratory distress syndrome following pulmonary resection. Ann Thorac Surg (in press).

57. Shoemaker WC, Appel PL, Kram HB, et al: Prospective trial of supranormal values of survivors as therapeutic goals in high-risk surgical patients. Chest 1988;94:1176-1188.

58. Durham RM, Neunaber K, MazuskI JE, et al: The use of oxygen consumption and delivery as endpoints for resuscitation in critically ill patients. J Trauma 1996;41:32-40.

59. Moore EE: Hypertonic saline dextran for post-injury resuscitation: experimental background and clinical experience. Aust NZ J Surg 1991;61:732-736.

60. Wade CE, Kramer GC, Grady JJ, et al: Efficacy of hypertonic $7.5 \%$ saline and $6 \%$ dextran-70 in treating trauma: a meta-analysis of controlled clinical studies. Surgery 1997;122:609-616.

61. Younes RN, Yin KC, Amino CJ, et al: Use of pentastarch solution in the treatment of patients with hemorrhagic hypovolemia: randomized phase II study in the emergency room. Word J Surg 1998;22:2-5.

62. Shackford SR, Bourguignon PR, Wald SL, et al: Hypertonic saline resuscitation of patients with head injury: a prospective, randomized clinical trial. J Trauma 1998;44:50-58.

63. Vassar JJ, Perry CA, Gannaway WL, et al: $7.5 \%$ Sodium chloride/ dextran for resuscitation of trauma patients undergoing helicopter transport. Arch Surg 1991;16:1065-1072.

64. Thangathurai D, Gharbonnet C, Wo CGJ, et al: Intraoperative maintenance of tissue perfusion prevents ARDS. New Horiz 1996;4:466-474.

65. Wang $\mathrm{P}$, Wheng FB, Zhou M, et al: Pentoxifylline restores cardiac output and tissue perfusion after trauma-hemorrhage and decreases susceptibility to sepsis. Surgery 1993;114:3520-3539.

66. Bacher A, Mayer N, Klimscha W, et al: Effects of pentoxifylline on hemodynamics and oxygenation in septic and nonseptic patients. Crit Care Med 1997;25:795-800.

67. Sun X, Wagner DP, Knaus WA: Does selective decontamination of the digestive tract reduce mortality for severely ill patients? Crit Care Med 1996;24:753-755. 
68. Luiten EJ, Hop WCJ, Lange JF, Bruining HA: Controlled clinical trial of selective decontamination for the treatment of severe acute pancreatitis. Ann Surg 1995;222:57-65.

69. Baxby D, van Saene HKKF, Stoutenbeek CP, Zandstra DF: Selective decontamination of the digestive tract: 13 years on, what it is and what it is not. Intensive Care Med 1996;22:699-706.

70. Kolla S, Awad SS, Rich PB, et al: Extracorporeal life support for 100 adult patients with severe respiratory failure. Ann Surg 1997;226:544-566.
71. Hirasawa H, SugaI T, Oda S, et al: Continuous hemodiafiltration (Ghdf) removes cytokine and improves respiratory index (Ri) and oxygen metabolism in patients with acute respiratory distress syndrome (ARDS). Crit Care Med 1998;26:A120.

72. Honore PM, James J, Wauthier M, et al: Reversal of intractable circulatory failure complicating septic shock with short time high volume haemofiltration (ST-HV-CWH) after failure of conventional therapy: a prospective evaluation. Crit Care 1998;2:62. 